\title{
Precise seeding planter concept with air pumped seedtube
}

\author{
Ilia Markvo $^{1, *}$, Elena Zubrilina ${ }^{1}$, and Vitaliy Novikov ${ }^{1}$ \\ ${ }^{1}$ Don State Technical University, Rostov-on-Don, Russia
}

\begin{abstract}
The current methods for seed placement in row planting equipment is accomplished with a variety of mechanically driven vehicles. In this context, robotics and automation play a crucial role. However, agricultural working environments require specific solutions regarding positioning and motion control of autonomous vehicles. Our research involves the process of modern sowing device's designing and developing. The technical result is in the increase in functionality by ensuring quality control of sowing, determining the seed speed during sowing and the possibility of changing the seed speed during sowing. The proposed utility design has many advantages compared with the prototype and other wellknown technical solutions.
\end{abstract}

\section{Introduction}

During the cultivation of the agricultural crops, an especially important role is given to meeting the requirements for the distribution of the seeds in the soil. Accuracy of seed positioning in the soil is one of the determining factors that give maximum yield at minimum cost of the crop cultivation [1]. At the same time, according to the existing quality standards, a tilled seeding planter should sow at least $95 \%$ of seeds that fulfill agrotechnical requirements $[2,3]$. The performance quality of the technological sowing operations and the constructive fulfillment of the seeding planter also have an important influence [4-6].

\section{Research status and work relevance}

Modern tilled seeding planters have various design peculiarities and a number of technical solutions. At a low location of the sowing device, a seedtube is not provided, thus the fall of the seeds from the sowing device to the bottom of the furrow is free, and this process is probabilistic in nature. This is a problem and affects the quality of sowing, especially at high speeds.

At a high location of the sowing device, the seedtube is introduced into the design of tilled seeding planters, and ensures the delivery of the seeds from the sowing device to the bottom of the furrow. But this is only relevant for seeding planters with the location of the sowing device on the frame of the seeding planter. The seedtube (figure 1) is a tube 1 of a

\footnotetext{
${ }^{*}$ Corresponding author: iluhan_markvo@mail.ru
} 
circular cross section, which is attached to the sowing device through the bracket 2 with a hose clamp 3.

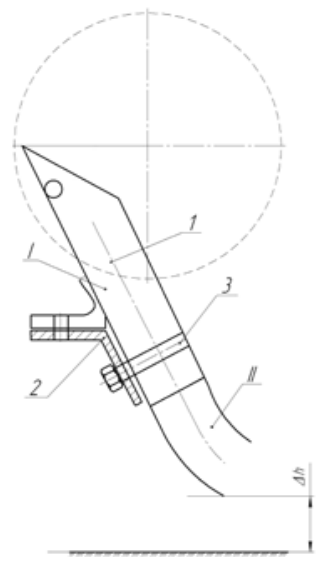

Fig. 1. Diagram of a typical seed tube for precise seeding planters.

The presented seedtube has two segments: rectilinear I and curvilinear II. This design allows setting the trajectory of the seed. In the segment I, the seed falling from the sowing disk is placed on the gutter-like inner surface of the seed tube and slides along it as if on an inclined plane to the segment II. In the segment II, the seed moves along a curvilinear surface of constant radius until it descends from the seedtube and then reaches the bottom of the furrow.

Having analyzed the device classification of precise seeding planters [7], as well as a number of modern patents of sowing devices, we proposed a new classification feature in the design of the tilled seeding planter - the level of the sowing device location (figure 2). This classification feature is typical both for domestic production seeding planters and for foreign machines.

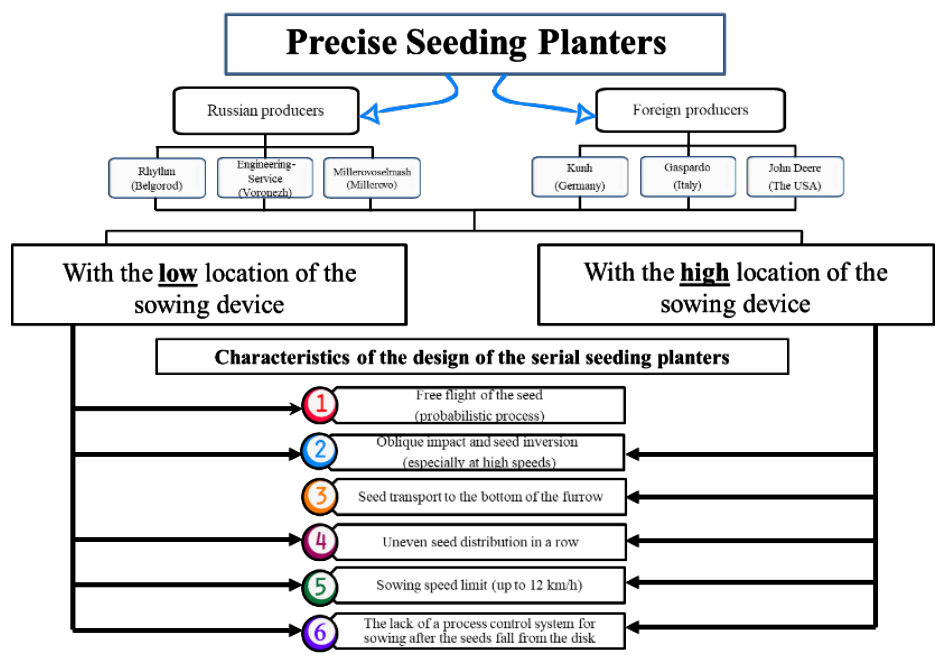

Fig. 2. Classification of precise seeding planters according to the location of their sowing devices.

In addition, figure 2 shows the main drawbacks of modern seeding planters. The following drawbacks inherent in both variants should be pointed out: the limitation associated with high sowing speed of $12 \mathrm{~km} / \mathrm{h}$, the existance of the oblique impact and the 
inversion of the seeds, which adversely affects exact positioning of the seeds in the soil, and as a result, there is uneven distribution of the seeds in a row and the complete lack of opportunity to control the sowing process after the seeds have fallen from the disk.

\section{Formulation and solution of the problem}

In the serial seeding planters of foreign and domestic producers, there are widely presented systems that only regulate the quality control of seeding and monitor the sowing process. Regardless of the design of the seeding planter, there is currently no solution on the market that would allow managing the sowing process directly during the operation of the seeding planter.

We believe that the solution of the above mentioned problems lies in the synthesis of the performance technology of the sowing device, a hybrid design with a low location of the sowing device and the seedtube that allows the ability to control the speed of the seeds flight.

There is a well-known design [8] of the pneumatic sowing device having a seedtube with three segments, apart from rectilinear and curvilinear, shown in figure 1, there is an accelerator segment in the design of the seedtube, which allows using the air flow to accelerate the seeds to a speed equal to the magnitude of the sowing device speed and thus providing a zero seed speed relative to the soil at the time of contact with the furrow.

Figure 3 shows the visualization of the way to improve this design.

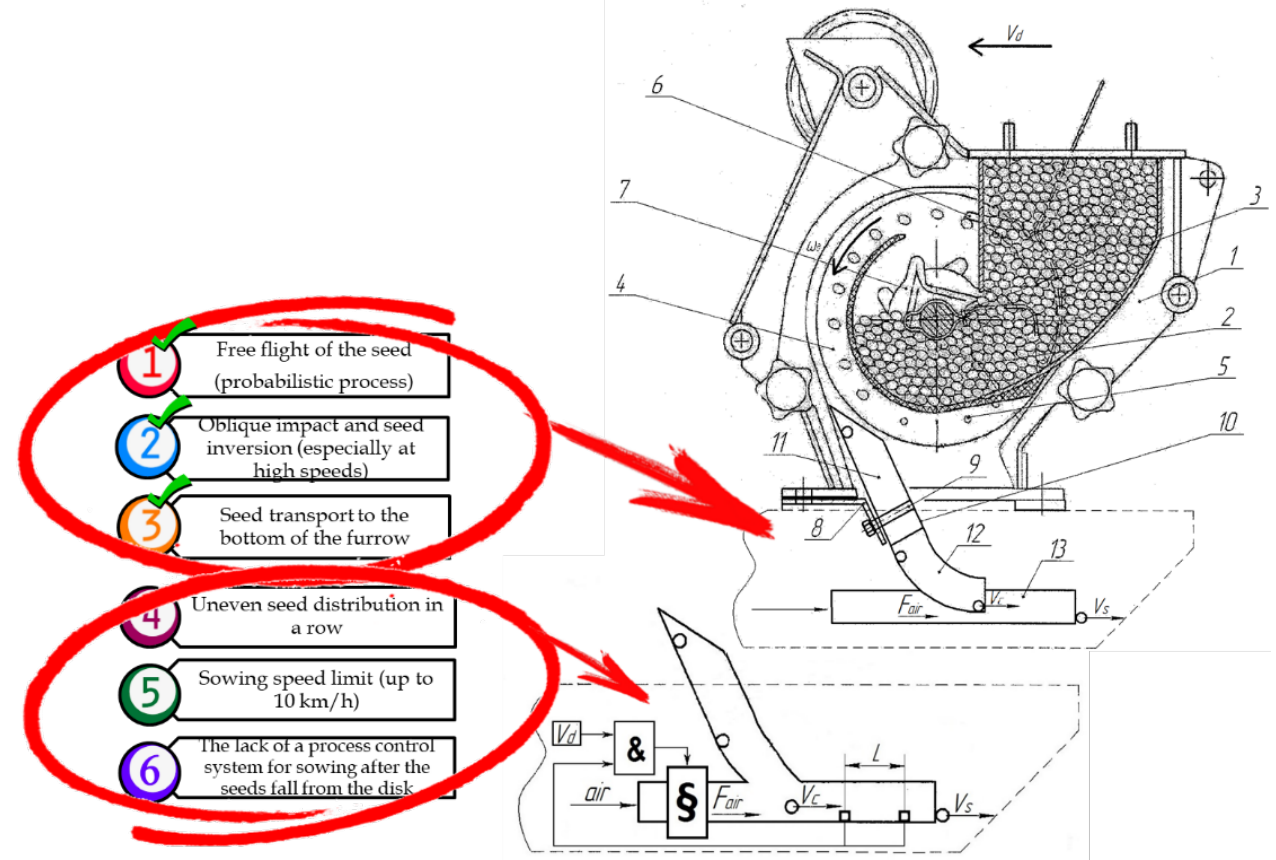

Fig. 3. Diagram of the improved sowing device with the seed tube.

Having done a review of the modern precise seeding planters designs and a patent search for the latest technical solutions [9], we developed a functional scheme and the design of the improved sowing device with the seedtube and a system for automatic measuring of the seed speed as they leave the seedtube with the ability to control the seed speed (figure 4). 


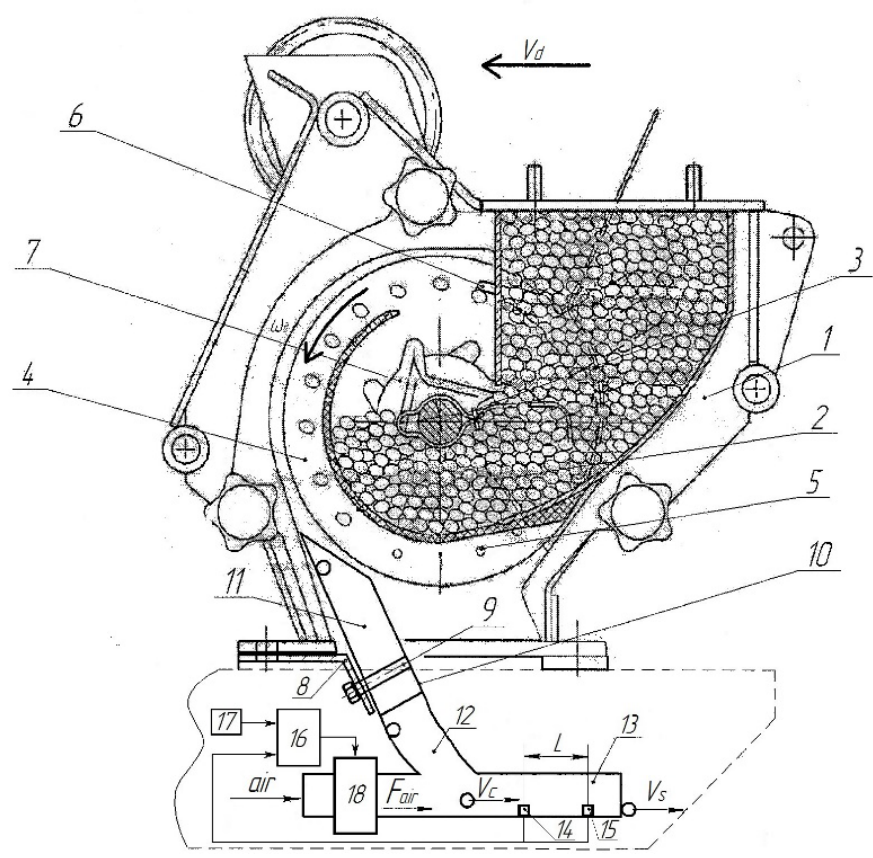

Fig. 4. Pneumatic sowing device with an automatic system for control and monitoring of sowing quality.

The pneumatic sowing device (figure 4) includes a housing 1 with a seed chamber 2 and a vacuum chamber (not shown in the figure), between which on the horizontal shaft 3 there is a sowing disc 4 with suction holes 5 and a plate reflector to remove the "extra" seeds 6 adjoining to the end plane of the sowing disc, and a central rubber tedder 7 is installed on the horizontal shaft 3 of the sowing disc. In the lower part of the housing 1 of the sowing device, through the bracket 8 , the seedtube 10 is fastened with a collar 9 . The seedtube is a tube of a circular cross section and it has three segments: rectilinear 11, curvilinear 12 and accelerator 13. The first 14 and second sensors 15 are located in the accelerator segment of the seedtube 13, while the outputs of the first and second sensors are connected to the corresponding inputs of the monitor and control unit 16, which receives a signal from the speed sensor of the seeding device 17. Besides, an air flow control unit 18 is installed (the throttle valve, comprising a housing that has a rotary disk connected to the servomotor shown in figure 5) at the beginning of the accelerator segment of the seedtube.

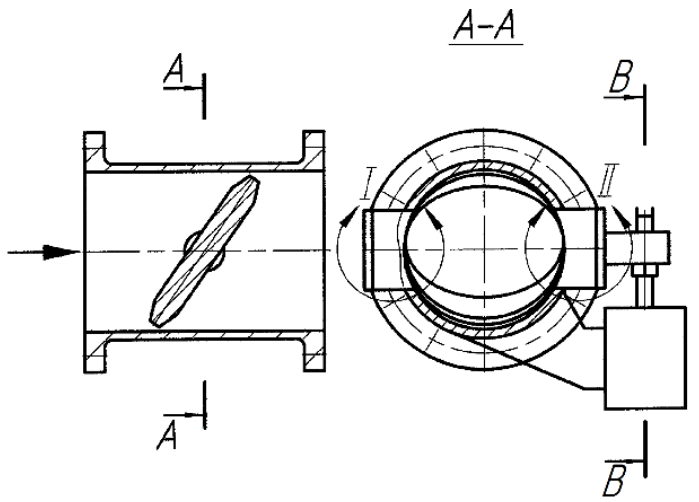

Fig. 5. Airflow control unit. 
The operation of the pneumatic sowing device is performed as follows. The seeds from a bunker (not shown in figure 4) enter the seed chamber 2 of the housing 1 of the sowing device, from which, under the influence of the rarefaction created in the vacuum chamber (not shown in the figure), they stick to the suction holes 5 of the sowing disc 4 . Rotating together with the sowing disk 4 , the seeds from the seed chamber 2 are transferred to a plate reflector 6 , under the influence of which the "extra" sucked seeds are returned back to the seed chamber 2 . Then the seeds are transported by the sowing disk 4 to the drop zone. The seed coming from the sowing disk is placed on the inner surface of the seedtube 10 in the rectilinear segment 11 and slides along it as on an inclined plane to the curved segment 12 . In the curved segment 12, the seed moves along a curved surface of constant radius until the velocity vector acquires a horizontal direction. When leaving the curvilinear segment 12 of the seedtube 10 at a speed $\mathrm{V}_{\mathrm{c}}$, the seed continues to move along the accelerator segment 13 , increasing its speed due to the force of the air flow. The air flow force $F_{\text {air }}$ in the accelerating segment 13 of the seedtube is determined by the air flow rate, which changes due to the airflow control unit 18 . In the accelerator segment 13 , the horizontally moving seed is accelerated by the air flow to a rate equal to the speed of the sowing device $V_{d}$. The air flow is regulated by changing the opening angle of the throttle valve located at the beginning of the accelerator segment. If the seed speed is equal to the speed of the sowing device, the zero seed speed is ensured relative to the soil, which leads to an increase in the even distribution of seeds along the length and width of the row during sowing various tilled crops. The seed speed value in the acceleration segment $V_{s}$ is determined by the first 14 and second sensors 15 , the speed of the sowing device $V_{d}$ is determined by the sensor 17. These values are sent to the monitor and control unit 16 , in which speeds are compared and the output of the control impact is performed for the throttle valve servo (airflow control unit) 18.

The technical result [10], which can be achieved using the proposed utility design, is in the increase in functionality by ensuring quality control of sowing, determining the seed speed during sowing and the possibility of changing the seed speed during sowing.

The proposed utility design is patented and has the following advantages compared with the prototype and other well-known technical solutions:

- eliminates the redistribution of the tilled crops seeds in a row during sowing;

- increases the even distribution of the tilled crops seeds in a row during sowing;

- monitors the speed of the sowing device movement and the speed of the seed flight, with the possibility of speed equalizing;

- allows to perform technological control of the sowing device operation during sowing.

In our proposed design, the information-measuring system was integrated into the structure of the sowing device, specifically: the introduction of the sensors unit into the curvilinear and accelerator segments of the seedtube and the monitor and control unit will allow monitoring the seed speed during sowing and adjust the air flow automatically. Such an upgrade will make it possible to automate the process of managing the quality of seeds sowing in dispensing systems.

The fundamental innovation of the proposed design of the sowing device includes the following components of the project:

- the presence of the seedtube with supply of the air flow (variable) in the design of the seeding planter, allowing to change the trajectory of movement from the sowing disk to the bottom of the furrow, as well as to change the velocity vector and its value;

- availability of a system for measuring the speed of the seeds as they leave the seedtube with air flow;

- a new approach in managing the quality of sowing of tilled crops based on automatic coordination of the speed of the sowing device and the speed of the seeds as they leave the seedtube; 
- the presence of an automated control unit of airflow strength;

- the introduction of the information and analytical system to monitor and control the sowing process.

Ensuring the movement of the seeds along a given trajectory and with the necessary speed, of course, improves the technological process of the tilled crops sowing with pneumatic seeding planters. We believe that with the introduction of an automated system of quality control and monitoring into the seeding planter, there will be an increase in yields and seed saving.

\section{References}

1. Hemlata Goyal, Nisheeth Joshi, Chilka Sharma, Procedia Computer Science, 132 (2015), https://doi.org/10.1016/j.aaspro.2015.12.010

2. PasiSuomia1TimoOksanenb, Computers and Electronics in Agriculture, 116 (2015), https://doi.org/10.1016/j.compag.2015.05.016

3. Søren Kirkegaard Nielsen, Lars Juhl Munkholm, Mathieu Lamandé, Michael Nørremark, Gareth T.C. Edwards, Ole Green, Computers and Electronics in Agriculture, 144 (2018), https://doi.org/10.1016/j.compag.2017.12.008

4. ChiranthHegde, HarryMillwater, MichaelPyrcz, HughDaigle, KenGray, Journal of $\begin{array}{lllll}\text { Natural Gas Science and } & \text { Engineering, }\end{array}$ https://doi.org/10.1016/j.jngse.2019.04.017

5. S. Kamgar, F. Noei-Khodabadi, S.M. Shafaei, Information Processing in Agriculture, 2 (2015), https://doi.org/10.1016/j.inpa.2015.08.001

6. Ahmad A. Al-Mallahi, Kataoka Takashi, IFAC Proceedings Volumes, 46, Issue 18 (2013), https://doi.org/10.3182/20130828-2-SF-3019.00011

7. Edmund Lorencowicz, Jacek Uziak, Agriculture and Agricultural Science Procedia, 7 (2015), https://doi.org/10.1016/j.procs.2018.05.025

8. Elena Zubrilina, Lyubov Vysochkina, Mikhail Danilov, Vladimir Maliyev, Engineering for Rural Development, 16 (2017)

9. Alexey N. Beskopylny, Viktor B. Rykov, Elena M. Zubrilina and Andrey D. Chistyakov, MATEC Web of Conferences, 226 (2018), https://doi.org/10.1051/matecconf/201822604034

10. Ilia Markvo, Elena Zubrilina, Vitaliy Novikom, Alexey Beskopylny, Lyubov Vysochkina, Dmitry Rudoy, Andrey Butovchenko, Interagromash, A concept of precise seeding planter with control and management system (to be published) 